\title{
ANALIZA WZMOCNIENIA PODŁOŻA POD KONSTRUKCJE NAWIERZCHNI DRÓG OBCIĄŻONYCH RUCHEM LEKKIM I ŚREDNIM WEDLUG KTKNPIP
}

\begin{abstract}
W roku 2015 roku uprawomocniło się rozporządzenie Ministra Infrastruktury i Rozwoju zmieniające rozporządzenie w sprawie warunków technicznych, jakim powinny odpowiadać drogi publiczne i ich usytuowanie (WT). Rozporządzanie to usunęło załącznik 4 i 5 do WT, dotyczący określenia warunków gruntowo-wodnych podłoża nawierzchni oraz typowych konstrukcji nawierzchni. Zmiany te wynikały przede wszystkim z opracowania na zlecenie GDDKiA nowego katalogu typowych nawierzchni: podatnych i półsztywnych (KTKNPiP) przez zespół prof. Judyckiego i nawierzchni sztywnych przez zespół prof. Szydło i wprowadzenia ich do obowiązkowego stosowania na drogach krajowych w 2014 roku. W artykule autorzy przenalizują zaproponowane typowe rozwiązania ulepszonego podłoża i dolnych warstw konstrukcji nawierzchni obciążonych ruchem KR1 $\div$ KR2 (ruch lekki) i KR3 $\div$ KR4 (ruch średni) oraz przedstawią autorskie równoważne rozwiązania.
\end{abstract}

Słowa kluczowe: podłoże gruntowe, ulepszone podłoże, wzmocnienie podłoża, konstrukcja nawierzchni

\section{Dotychczasowa praktyka}

Nazwy opisowe kategorii ruchu występowały tylko w katalogu z roku 1977 i jego nowelizacji z 1983 [2], mimo to do dnia dzisiejszego stosuje się budownictwie drogowym określania takie jak: ruch lekki, średni i ciężki. W ramach niniejszego artykułu pod pojęciem ruch lekki rozumie się kategorie ruchu $K R 1 \div K R 2$, natomiast pod pojęciem ruch średni kategorie ruchu $K R 3 \div K R 4$. Przyjęte przedziały są zgodne z aktualnymi przepisami dotyczących dróg m.in. WT-1 2014, WT-2 2014, katalogi [6, 7].

\footnotetext{
${ }^{1}$ Autor do korespondencji/corresponding author: Katedra Dróg i Mostów, Wydział Budownictwa i Architektury, Zachodniopomorski Uniwersytet Technologiczny w Szczecinie, stanislaw.majer@zut.edu.pl

${ }^{2}$ Katedra Dróg i Mostów, Wydział Budownictwa i Architektury, Zachodniopomorski Uniwersytet Technologiczny w Szczecinie, bartosz.budzinski@zut.edu.pl
} 
Od końca lat 70-tych XX wieku katalog typowych konstrukcji jezdni podatnych [2] wymagał aby podłoże pod konstrukcje charakteryzowało się nośnością $G 1 \mathrm{tj}$.

- grunt był niewrażliwy na działanie mrozu,

- nośność $w_{\text {nos }} \geq 10$ (po 4 dobach nasycenia wodą),

- zagęszczeniem zgodnym z wymaganiami normy PN-S 02205:1998.

Podłoże wg katalogu 1997 pod konstrukcje nawierzchni powinno być niewysadzinowe o grupie nośności Gl które charakteryzowało się zagęszczeniem i nośnością w zależności od kategorii ruchu:

- KR $1 \div K R 2$ - wtórny moduł $E_{2} \geq 100 \mathrm{MPa}$ i wskaźnik zagęszczenia $I_{S} \geq 1,00$,

- KR3 $\div K R 6$ - wtórny moduł $E_{2} \geq 120 \mathrm{MPa}$ i wskaźnik zagęszczenia $I_{S} \geq 1,03$.

$\mathrm{W}$ przypadku występowania w podłożu gruntów innej grupy nośności niż G1 podłoże należy wzmocnić. Podstawową metodą wzmacniania od roku 1977 do 2014 było wykonanie warstw stabilizacji. Drugą metodą była wymiana warstwy gruntu podłoża nawierzchni na warstwę gruntu lub materiału niewysadzinowego.

\section{Nowy katalog}

Nowy katalog nawierzchni podartych i półsztywnych został opracowany przez zespół prof. Judyckiego z Politechniki Gdańskiej. Autorzy przy pracach nad nowym katalogiem w stosunku do z roku 1997 uwzględniali [6]:

- postęp technologiczny w budowie dróg,

- wprowadzenie nowych norm i wymagań technicznych dostosowanych do normalizacji europejskiej,

- zmianę wymagań dotyczących materiałów stosowanych w konstrukcjach nawierzchni,

- znaczący wzrost natężenia ruchu pojazdów ciężarowych, zwiększony został dopuszczalny ciężar osi pojedynczych i wielokrotnych,

- wykonanie obliczeń konstrukcji nawierzchni w oparciu o nowe kryteria zmęczeniowe z metod mechanistyczno-empirycznych.

W katalogu 2014 zwrócono dużą uwagę na usystematyzowanie nazewnictwa oraz określenie ścisłej granicy pomiędzy spodem konstrukcji nawierzchni a poziomem robót ziemnych. Poziom niwelety robót ziemnych jest to poziom górnej powierzchni gruntu nasypowego w nasypie, lub poziom górnej powierzchni gruntu rodzimego w wykopie, ewentualnie poziom górnej powierzchni warstwy ulepszonego podłoża, o ile taka warstwa występuje [6].

Kolejną znacząca różnicą w stosunku do katalogu 1997 to wprowadzenie wymaganej nośności na powierzchni dolnych warstw konstrukcji nawierzchni wynoszącej odpowiednio dla kategorii ruchu $K R 1 \div K R 2 \quad E_{2} \geq 80 \mathrm{MPa}$, ruchu $K R 3 \div K R 4 E_{2} \geq 100 \mathrm{MPa}$ i dla ruchu $K R 5 \div K R 7 E_{2} \geq 120 \mathrm{MPa}$. Pozostawiono podział na 4 grupy nośności w zależności od wartości CBR uzupełniając go jednak 
Tabela 1. Klasyfikacja grup nośności podłoża gruntowego nawierzchni Gi

Table 1 . The classification groups load capacity of subgrade $\mathrm{Gi}$

\begin{tabular}{|c|c|c|}
\hline Grupa nośności & $\begin{array}{c}\text { Wskaźnik nośności } C B R \text { po } 4 \\
\text { dniach nasączania woda } \\
{[\%]}\end{array}$ & $\begin{array}{c}\text { Wtórny moduł odkształcenia } E_{2} \\
{[\mathrm{MPa}]}\end{array}$ \\
\hline $\mathrm{G} 1$ & $C B R \geq 10$ & $E_{2} \geq 80$ \\
\hline $\mathrm{G} 2$ & $5 \leq C B R<10$ & $50 \leq E_{2}<80$ \\
\hline $\mathrm{G} 3$ & $3 \leq C B R<5$ & $35 \leq E_{2}<50$ \\
\hline $\mathrm{G} 4$ & $2 \leq C B R<3$ & $25 \leq E_{2}<35$ \\
\hline
\end{tabular}

Przy określaniu $C B R$ jak i $E_{2}$ postępować zgodnie z zaleceniami normy PN-S 02205:1998

o wartości moduł $E_{2}$ (tabela 1). Pozostawiono możliwość określenia grupy nośności na podstawie wysadzinowości gruntów oraz warunków wodnych, zmieniono jednak w kilku przypadkach grupy nośności na bezpieczniejsze w stosunku do wcześniejszych wymagań.

\section{Wzmocnienie podłoża wg katalogu 2014 na ruch lekki i średni}

Dolne warstwy konstrukcji nawierzchni mogą składać się z następujących warstw (pojedynczo lub w układach z 2 warstw):

- podbudowy pomocniczej (PP) wykonanej z mieszanek lub gruntów związanych spoiwem hydraulicznym $\mathrm{C}_{3 / 4}$ przewidzianej do zastosowania konstrukcji nawierzchni dla kategorii ruchu $K R 3 \div K R 4$,

- warstwy mrozoochronnej (WM) wykonanej z mieszanek lub gruntów stabilizowanej spoiwem hydraulicznym $\mathrm{C}_{1,5 / 2}$, mieszanek niezwiązanych i gruntów niewysadzinowych.

W tabeli 2 przedstawiono wyniki obliczeń modułu zastępczego wykonanego dla całego pakietu warstw podanych w opracowaniu [4]. W dwóch przypadkach uzyskano wartości mniejsze modułu niż wymagane, w pierwszym $E_{z a s t}=95 \mathrm{MPa}$ ale w przypadku wykonania obliczeń z uwzględnieniem modułu

Tabela 2. Wyniki obliczeń modułów zastępczych dla całego pakietu warstw, na podstawie [4]

Table 2. The results of the modules substitute calculation for the total package of layers, based on [4]

\begin{tabular}{|c|c|c|c|c|c|c|}
\hline \multirow{2}{*}{$\begin{array}{c}\text { Kategoria } \\
\text { ruchu }\end{array}$} & $\begin{array}{c}\text { Grupa } \\
\text { nośności } \\
G i\end{array}$ & \multicolumn{5}{|c|}{ Wartości obliczonego modułu zastępczego [MPa] } \\
\cline { 3 - 7 } & Typ 5 & Typ 6 & Typ 7 & Typ 8 & Typ 9 \\
\hline \multirow{4}{*}{ KR3 - KR4 } & G4 & 131 & 103 & $95^{*}$ & 102 & 101 \\
\cline { 2 - 7 } & G3 & 146 & 114 & 106 & 113 & 111 \\
\cline { 2 - 7 } & G2 & 149 & 116 & 100 & 111 & 114 \\
\cline { 2 - 7 } & G1 & 145 & 145 & 122 & 130 & 125 \\
\hline \multirow{5}{*}{ KR1 - KR2 } & & Typ 10 & Typ 11 & Typ 12 & Typ 13 & Typ 14 \\
\cline { 2 - 7 } & G4 & 80 & 77 & 95 & 108 & 83 \\
\cline { 2 - 7 } & G3 & 90 & 84 & 101 & 109 & 84 \\
\cline { 2 - 7 } & G2 & 84 & 84 & 100 & 100 & 83 \\
\hline
\end{tabular}


na warstwie ulepszonego podłoża wynosi on $100 \mathrm{MPa}$, w drugim różnica pomiędzy wymaganą wartością wynosi jedynie $3 \mathrm{MPa}$.

\section{Propozycje nowych pakietów warstw konstrukcji nawierzchni i ulepszonego podłoża}

Znakomitą większość dróg publicznych w Polsce stanowią drogi gminne i powiatowe. Na koniec 2013 roku długość sieć dróg publicznych w Polsce wyniosła 415132,6 km [1]. Z tego drogi krajowe stanowiły 4,6\%, drogi wojewódzkie 6,9\%. W przypadku dróg krajowy długość dróg klasy G wynosiła 4446 km, a średnio dobowy ruch roczny (SSDR) pojazdów ciężkich na podstawie GPR 2015 wynosił 757 poj./dobę, co odpowiada kategorii ruchu KR4 [5]. Można więc bez popełnienia znaczącego błędu stwierdzić, że $90 \%$ ogółu dróg publicznych w Polsce jest obciążone ruchem kategorii $K R l \div K R 4$. Z uwagi na niewystarczające zasoby finansowe gmin i powiatów, każda możliwa oszczędność wynikająca np. z mniejszej głębokości korytowania, zastosowania kruszyw z recyklingu, jest pożądana. Dlatego też, autorzy wykonali obliczenia dolnych warstw konstrukcji nawierzchni i ulepszonego podłoża składających się z gruntów i mieszanek stabilizowanych spoiwami hydraulicznymi oraz mieszanki niezwiązanej $\mathrm{z}$ betonu przekruszonego o $\mathrm{CBR} \geq 60 \%$, spełniającej wymagania WT-4 2010 .

Wymagane grubości dolnych warstw konstrukcji nawierzchni oraz ulepszonego podłoża wyznaczono analogicznie jak katalogu 2014. Moduły zastępczy wyznaczono na podstawie wzoru Boussinesq'a [4], również stałe materiałowe przyjęto do obliczeń identyczne jak w przypadku katalogu [4].

Propozycje dolnych warstw konstrukcji nawierzchni dla kategorii ruchu $K R 1 \div K R 2$ przedstawiono w tabeli 3 dla kategorii ruchu $K R 3 \div K R 4 \mathrm{w}$ tabeli 4 . Dla warstw wykonywanych podczas procesu mieszania, ulepszania gruntu na miejscu przyjęto, że maksymalna grubość takiej warstwy po zagęszczeniu może wynieść $35 \mathrm{~cm}$. Również przyjęto odmienne w stosunku do autorów katalogu 2014 założenia, co do stosowania mieszanki związanej spoiwem hydraulicznym $\mathrm{C}_{3 / 4}$. W zaproponowanych rozwiązaniach uwzględniono jej zastosowanie również w przypadku kategorii ruchu KR $1 \div K R 2$. Rozwiązanie takie umożliwia bowiem znaczną redukcje grubości. W tabeli 5 i 6 podano grubości typowych rozwiązań wg katalogu i propozycji autorów.

Zaproponowane układy dolnych warstw konstrukcji nawierzchni spełniają warunek mrozoodporności głębokości przemarzania $h_{z}=0,8 \mathrm{~m}$ dla typowych konstrukcji górnych warstw nawierzchni TYP A1 (podbudowa zasadnicza z kruszywa łamanego stabilizowanego mechanicznie $\mathrm{C}_{90 / 3}$ ). Natomiast w przypadku głębokości przemarzania $h_{z}=1,0 \mathrm{~m}$ zaproponowane układy dolnych warstw konstrukcji nawierzchni spełniają warunek mrozoodporności dla kategorii ruchu $K R I \div K R 2$ dla grupy nośności $G 2$, dla kategorii ruchu $K R 3 \div K R 4$ wymagania spełnia typ III, typ IV oraz typ V natomiast TYP VI nie spełnia dla 
Tabela 3. Propozycja rozwiązań warstw dolnych konstrukcji nawierzchni i warstwy ulepszonego podłoża dla kategorii ruchu $K R 1 \div K R 2$

Table 3. The offer solutions to lower layers of pavement structure and the improved subgrade layers for traffic $\mathrm{KR} 1 \div \mathrm{KR} 2$

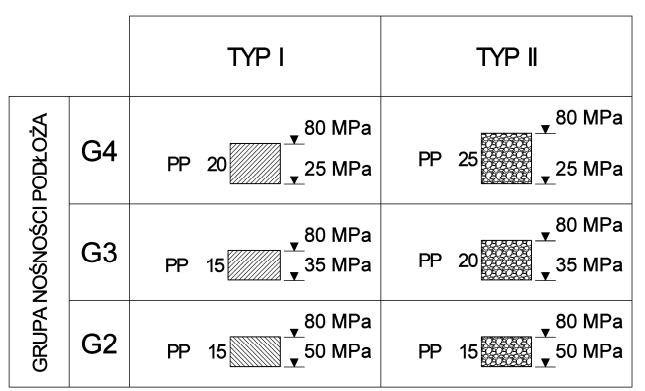

1.1/1/A Podbudowa pomocnicza z mieszanki związanej spoiwem hydraulicznym $C_{3 / 4}$

Podbudowa $z$ destruktu betonowego $\mathrm{C}_{50 / 30} \circ \mathrm{CBR} \geq 60 \%$

1 Podbudowa pomocnicza z mieszanki związanej spoiwem hydraulicznym lub $\mathrm{z}$ gruntu stabilizowanego spoiwem $\mathrm{C}_{15 / 2}$

Warstwa ulepszonego podłoża z gruntu stabilizowanego spoiwem $C_{0,410,5}$

Tabela 4. Propozycja rozwiązań warstw dolnych konstrukcji nawierzchni i warstwy ulepszonego podłoża dla kategorii ruchu $K R 3 \div K R 4$

Table 4 . The offer solutions to lower layers of the pavement structure and the improved subgrade layers for traffic KR $3 \div \mathrm{KR} 4$

\begin{tabular}{|c|c|c|c|c|c|c|}
\hline & & TYP III & TYP N & TYP V & TYP V & TYP VI \\
\hline \multirow{4}{*}{ 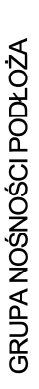 } & G4 & $\begin{array}{ll}\text { PP } & 15 \\
\text { WUP } & 20 \\
25 \mathrm{MPa}\end{array}$ & $z^{*}$ & 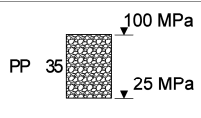 & 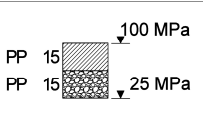 & $25 \mathrm{MPa}$ \\
\hline & G3 & $\begin{array}{rr}\text { PP } & 15 \\
\text { WUP } & 15 \\
\mathbf{x}^{100 \mathrm{MPa}} & 35 \mathrm{MPa}\end{array}$ & $\begin{array}{l}100 \mathrm{MPa} \\
.35 \mathrm{MPa}\end{array}$ & $v^{35 \mathrm{MPa}}$ & $\begin{array}{ll}\text { PP } & 15 \\
\text { PP } & 15 x^{15}\end{array}$ & $\begin{array}{l}100 \mathrm{MPa} \\
\tau^{35 \mathrm{MPa}}\end{array}$ \\
\hline & G2 & PP 15 पाm $\begin{array}{l}100 \mathrm{MPa} \\
50 \mathrm{MPa}\end{array}$ & $\begin{array}{l}100 \mathrm{MPa} \\
50 \mathrm{MPa}\end{array}$ & $\begin{array}{l}100 \mathrm{MPa} \\
50 \mathrm{MPa}\end{array}$ & $\begin{array}{l}100 \mathrm{MPa} \\
50 \mathrm{MPa}\end{array}$ & $\begin{array}{l}100 \mathrm{MPa} \\
+50 \mathrm{MPa}\end{array}$ \\
\hline & G1 & StosowaćtypN & 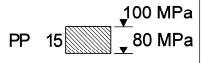 & 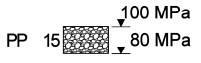 & StosowaćtypN & StosowaćtypN \\
\hline
\end{tabular}

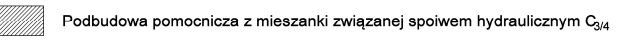

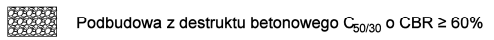

(1) Podbudowa pomocnicza z mieszanki związanej spoiwem hydraulicznym lub z gruntu stabilizowanego spoiwem $G_{, 5 / 2}$

Warstwa ulepszonego podłoża z gruntu stabilizowanego spoiwem $C_{0,40,5}$ 
Tabela 5. Porównanie grubości w cm warstw dolnych konstrukcji nawierzchni i warstwy ulepszonego podłoża dla kategorii ruchu $K R 1 \div K R 2$

Table 5. The comparison of thicknees of lower layers of the pavement structure and the layers of improved subgrade for the traffic category KR $1 \div \mathrm{KR} 2$

\begin{tabular}{|c|c|c|c|c|c|c|}
\hline \multirow{2}{*}{$G i$} & \multicolumn{6}{|c|}{$K R 1 \div K R 2$} \\
\hline & TYP 10 & TYP 11 & TYP 12 & TYP 13 & TYP 14 & średnia \\
\hline G4 & 30 & 45 & 46 & 55 & 65 & 48,2 \\
\hline G3 & 22 & 37 & 37 & 40 & 45 & 36,2 \\
\hline G2 & 15 & 15 & 22 & 22 & 25 & 19,8 \\
\hline G1 & - & - & - & - & - & - \\
\hline$G i$ & \multicolumn{3}{|c|}{ TYP I } & \multicolumn{2}{|c|}{ TYP II } & średnia \\
\hline G4 & \multicolumn{3}{|c|}{20} & \multicolumn{2}{|c|}{25} & 22,5 \\
\hline G3 & \multicolumn{3}{|c|}{15} & \multicolumn{2}{|c|}{20} & 17,5 \\
\hline G2 & \multicolumn{3}{|c|}{15} & \multicolumn{2}{|c|}{15} & 15 \\
\hline G1 & \multicolumn{3}{|c|}{ - } & \multicolumn{2}{|c|}{ - } & - \\
\hline
\end{tabular}

Tabela 6. Porównanie grubości w cm warstw dolnych konstrukcji nawierzchni i warstwy ulepszonego podłoża dla kategorii ruchu $K R 3 \div K R 4$

Table 6. The comparison of thicknees of lower layers of the pavement structure and the layers of improved subgrade for the traffic category KR $3 \div \mathrm{KR} 4$

\begin{tabular}{|c|c|c|c|c|c|c|}
\cline { 1 - 2 }$G i$ & KR3 - KR4 & \multicolumn{5}{|l|}{} \\
\cline { 1 - 2 } & TYP 5 & TYP 6 & TYP 7 & TYP 8 & TYP 9 & średnia \\
\hline G4 & 60 & 58 & 47 & 53 & 64 & 56,4 \\
\hline G3 & 55 & 43 & 42 & 48 & 49 & 47,4 \\
\hline G2 & 35 & 18 & 22 & 28 & 24 & 25,4 \\
\hline G1 & 15 & 15 & 18 & 22 & 15 & 17 \\
\hline G4 & TYP III & TYP IV & TYP V & TYP VI & TYP VII & średnia \\
\hline G3 & 35 & - & 35 & 30 & 33 & 33,3 \\
\hline G2 & 30 & 35 & 30 & 30 & 22 & 29,4 \\
\hline G1 & 15 & 25 & 20 & 15 & 15 & 18,0 \\
\hline & 15 & 15 & 15 & 15 & 15 & 15,0 \\
\hline
\end{tabular}

grupy nośności G4 a typ VII dla grupy nośności G3 i G4. Wówczas należy pogrubić dolne warwy konstrukcji nawierzchni albo zastosować typową konstrukcje górnych warstw nawierzchni i większej grubości np. TYP A2 lub TYP A3. Należy zaznaczyć, że głębokość przemarzania $h z=0,8$ m obejmuje znaczną część terenu Polski (całe województwo lubuskie i zachodnio-pomorskie, dużą część województwa wielkopolskiego i dolnośląskiego oraz fragmenty województwa pomorskiego i kujawsko-pomorskiego) co stanowi duży potencjalny obszar stosowania proponowanych rozwiązań i niesie możliwość poczynienia znacznych oszczędności przy zmniejszeniu grubości dolnych warstw konstrukcji przy jednoczesnym wykorzystaniu materiałów pochodzących z recyklingu. 


\section{Podsumowanie}

1. Zaproponowano alternatywne układy dolnych warstw konstrukcji nawierzchni i ulepszonego podłoża w stosunku do katalogu.

2. Nowe siedem typów dolnych warstw konstrukcji nawierzchni i ulepszonego podłoża spełnia wymagania nośności dla kategorii ruchu $K R l \div K R 2(80 \mathrm{MPa})$ i $K R 3 \div K R 4-100 \mathrm{MPa}$ obliczone zgodnie $\mathrm{z}$ metodologią zastosowaną $\mathrm{w}$ ramach obliczeń konstrukcji zaproponowanych w katalogu 2014.

3. Grubości nowych układów dolnych warstw konstrukcji nawierzchni i WUP są znacząco cieńsze dla typowych rozwiązań z katalogu 2014 w przypadku grupy nośności G3, G4.

4. Zaproponowane rozwiązania spełniają warunek mrozoodporności głębokości przemarzania $h_{z}=0,8 \mathrm{~m}$ oraz częściowo dla głębokości przemarzania $h_{z}=1,0 \mathrm{~m}$.

5. W zaproponowanych układach przewidziano zastosowanie mieszanki niezwiązanej z betonu przekruszonego (recykling betonowy), a więc materiału dostępnego - miejscowego, w związku z tym z reguły zdecydowanie tańszego od innych materiałów.

W publikacji przedstawiono propozycję pewnych rozwiązań, jednak niewątpliwe przydane byłoby szersze opracowanie rozwiązań uwzględniających różne materiały budowlane, które przede wszystkim byłyby tanie i zarazem akceptowalne przez inwestorów. Materiały te stanowiłby też wielkie ułatwienie dla projektantów, którzy w przypadku dróg lokalnych korzystają głównie z rozwiązań typowych i katalogowych.

\section{Literatura}

[1] Główny Urząd Statystyczny, Transport drogowy w Polsce w latach 2012 i 2013. Zakład Wydawnictw Statystycznych, Warszawa 2015.

[2] IBDiM, Katalog typowych konstrukcji jezdni podatnych, (wydanie I), (wydanie II znowelizowane).Warszawa 1977/1983.

[3] IBDiM, Katalog typowych konstrukcji nawierzchni podatnych i półsztywnych. Warszawa 1997.

[4] Judycki J. i inni,. Analizy i projektowanie konstrukcji nawierzchni podatnych i półsztywnych, WKŁ, Warszawa 2012.

[5] Opoczyńskie K., Synteza wyników GPR 2015 dla dróg krajowych. Transprojektwarszawa Sp. z o.o. Warszawa 2016 (http://www.gddkia.gov.pl/userfiles/articles/ g/generalny-pomiar-ruchu-w-2015_15598//SYNTEZA/Synteza_GPR2015.pdf), Warszawa 2015.

[6] Politechnika Gdańska, Katalog typowych konstrukcji nawierzchni podatnych i półsztywnych, GDDKiA, Załącznik do zarządzenia Nr 31 Generalnego Dyrektora Dróg Krajowych i Autostrad z dnia 16.06.2014 r., Warszawa 2014.

[7] Politechnika Wrocławska, Katalog typowych konstrukcji nawierzchni sztywnych, GDDKiA, , Załącznik do zarządzenia Nr 30 Generalnego Dyrektora Dróg Krajowych i Autostrad z dnia 16.06.2014 r., Warszawa 2014. 


\section{ANALYSIS STRENGTHEN THE SUBSOIL FOR THE CONSTRUCTION OF ROADS TRAFFICKED BY LIGHT AND MODERATE CATALOGUE OF TYPICAL FLEXIBLE AND SEMI-RIGID PAVEMENT STRUCTURES 2014}

\section{S u m m a r y}

In 2015 The Ministry of Infrastructure and Development passed a new ordinance about Road technical conditions. In the ordinance appendixes 4 and 5 was removed. The Appendixes affected ground-water conditions for pavement subgrade and typical road pavement constructions. These changes resulted from new Catalogue of typical flexible and semi-rigid pavement structures and new Catalogue of typical rigid pavement structures, which were evolved to order General Directorate for National Roads and Motorways. Those Catalogues were created by the teams of professors Judycki and Szydło. The Catalogues have been in force for every National Roads since 2014. The authors have analyzed typical solutions of an improved subgrade and a subbase for light and average traffic (KR1-KR4), and they have presented the own solutions.

Keywords: subgrade, improved subgrade, pavement construction

Przestano do redakcji: 07.06.2016 r.

Przyjęto do druku: 30.06.2016 r.

DOI: $10.7862 / r b .2016 .64$ 